\title{
Debate For and Against Euthanasia in the Control of Dog Populations
}

\author{
Antonio Ortega-Pacheco and Matilde Jiménez-Coello \\ Universidad Autonoma de Yucatan, \\ Mexico
}

\section{Introduction}

Dogs share the same environment of humans and play an important role in their ecological adjustment. Since its domestication 12,000 to 15,000 years ago, they have been part of human evolution with increases on its population as humans settle down. Dogs provide social and health benefits to humans but they may also be involved in social conflicts such as bites, zoonosis, destruction of ecosystems, etc. As consequence of its uncontrolled and logarithmic growth on its population, several strategies have been taken in both developed and developing countries. Under these two scenarios, euthanasia is employed as part of the strategy to overcome the surplus of this species. However, ethical issues arise when healthy dogs are killed or methods used for euthanasia are inhumane and against international standards. Besides, euthanasia as a method to control the dog overpopulation has shown to be expensive and ineffective on long term. In humans euthanasia is restricted to compassion or "mercy" killing to relief the patient of an terminal disease or when life become too painful and with poor life expectative. In veterinary medicine the term euthanasia is broader since it also includes healthy animals such as dogs, for elective euthanasia considering owner convenience, reasons of overpopulation, for behavior problems or research purposes.

Canine overpopulation arises when uncontrolled breeding of dogs and irresponsible ownership act together. Dogs are promiscuous species by nature and since not a well defined seasonality occurs in this species, are ready to mate all through the year. Owners frequently claim their rights to own a dog but may be reluctant to take care of their responsibilities. If no laws to regulate dog ownership exist or if they exists but are not reinforced, the imminent consequence will be a surplus of the species ending on the streets or shelters. Even in shelters, it is estimated that 2 out of 3 animals entering a shelter won't have a chance to be adopted and have to be euthanized.

Several methods for euthanasia in dogs have been used. Some are recommended by international associations and others are considered illegal in some countries. Barbiturates (pentobarbitone or pentobarbital sodium) are by most the more common used drug for euthanasia in dogs; barbiturates cause deep anesthesia and unconsciousness before leading to respiratory failure. However, in case of anesthetized animals other methods such as Magnesium sulfate, potassium salts, carbon monoxide gas and even captive bolt shots can be administrated. Some inacceptable methods, still used in some countries are the use of 
strychnine, electrocutation, cyanide, decapitation, drowning and curariform drugs (for example, succinylcholine).

This manuscript describes the situation of canine overpopulation and strategies to control it with special reference to the use of euthanasia. The use of mass euthanasia of stray dogs in developing countries and euthanasia performed in dog shelters will also be addressed. A fair description of methods used for euthanasia will be described. A general discussion about ethical and moral issues about the use of euthanasia methods to control the population of dog over plus and better strategies to address the problem will be generated.

\section{Canine overpopulation and welfare}

Dogs may be classified according to the level of supervision as restricted or supervised dogs (Fully dependent and fully restricted or supervised), family dogs (fully dependent; semirestricted) which can have access to the streets, neighbourhood dog (semi-dependent, semirestricted or unrestricted) and feral dog (independent, unrestricted, nobody takes responsibilities for it) (World Health Organization [WHO], 1990). Neighbourhood dogs are recognized as the most common kind of dog present in urban and rural areas from developing countries (Brooks, 1990; Orihuela \& Solano, 1995; Fielding \& Plumridge, 2005); those dogs are not necessary straying since may be allowed for freely roaming. In figure 1 an owned free roaming dog can be seen. Dog populations are very dynamics; after an initial exponential growth, the birth rate begins to decrease and the rate of death increases reaching equilibrium depending on the capacity of the environment to keep this balance (carrying capacity of the environment). The carrying capacity of the environment varies with habitat and it depends on the availability, distribution, and quality of the resources (shelter, food, water). In most cases if no control measures are taken, the density of a population of dogs is near the carrying capacity of the environment (WHO, 1990). The increasing in the number of dogs in a community may vary according to different habitats, cultures, and socio-economical structures of human rural and urban populations and to different epidemiological situations (Brooks, 1990; Margawani \& Robertson 1995; Fielding \& Plumridge 2005). Attitudes towards dogs have a great impact on its abundance and welfare. In developing countries dogs are relinquished and abandon to the streets by several reasons and become part of a stray population. India has one of the highest densities of stray dogs due to a large amount of edible litters on the streets, cultural tolerance of dogs and lack of consistently employed, sustained control programs (Butcher, 1999). As consequence, general health status of stray dogs is bad with thin to emaciate body condition, skin conditions and tick infestation (Totton et al., 2011). One of the critical factors leading to a fast growth of the canine population is the lack of control of birth rates as a result of failure to spay and castrate or to supervise pets. Free-roaming dogs, as a consequence, have indiscriminate promiscuity and a high birth rate achieving their maximal breeding efficiency. As result, most dogs are donated to other owners. These low or no cost pups can be responsible for a high number of the abandoned dogs (Hsu et al., 2003) or high number of unwanted dogs sent to the pounds. In developed countries few dogs become stray but are relinquished to dog shelters including pure breeds. Although it is assumed that paying a large amount of money for a pure breed dog will ensure good care an permanent home, this is untrue and frequently the most popular breed are relinquished in greatest numbers (Available at: www.isaronline.citymax.com). A population model based on dogs in the USA, used a birth and death rate of $12 \%$ and a turnover rate of $14 \%$, which included stray dogs returning to 
the population of owned dogs. Of the dogs that died in this model (6.2 million), over a third (2.4 million) died in shelters (Patronek \& Rowan, 1995).

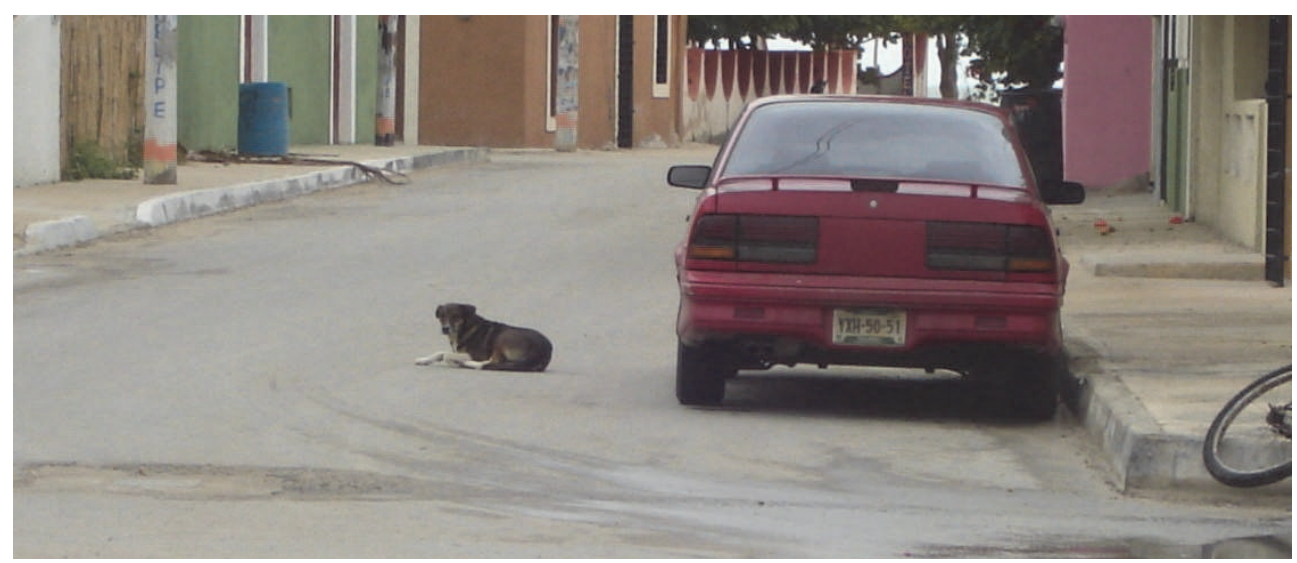

Fig. 1. An owned free roaming dog in a city

\section{Methods of dog control population}

There are many strategies to control dog populations but whatever the method used it should be based on ethical standpoints and/or practical experiences according to national/local situation avoiding animal suffering and when possible killing through effective, preventative programs. This ensures humane and sustainable solutions. Any program that only concentrates on the 'end result' such as euthanasia is provisional and do not solve the original problem. Strategies to control the overpopulation of free-roaming dogs include enforcement of law, education of owners and sterilization of pets. Dog-control programs are more widely used among the more-developed countries. In less-developed countries, dog control programs (when they existed at all) tended to employ killing methods (including poisoned baits), that are not recommended on animal-welfare grounds (Dalla Villa et al., 2010). Mass culling of stray dog population has historically been used to control rabies in India (Reece, 2007). Rabies has a high incidence in dogs in areas where dog populations reach high densities and where animals are poorly supervised (Wandeler \& Bingham, 2000). Recommended control measures for dog rabies control include movement restriction, reproduction control, habitat control and removal of straying dogs. The removal of straying dogs by killing strategies cannot be effective in long term without the enforcement of laws and education of people. Free ranging domestic dogs are noncooperative populations, i.e. they are not dependant on other animals of the same species to survive so any reduction in the population density through additional mortality is rapidly compensated by better reproduction and survival, and removal of the population to its maximum carrying capacity. In many developed countries stray dogs is a problem that has never risen because of different sanitary and ecological conditions but most important because of licensing programs, public education for responsible ownership and welldeveloped re-homing shelters. 
Reducing birth rates may have a great influence in reducing dog relinquishment and consequently euthanasia. Surgical neutering is by far the most common method of birth control in dogs but it's too expensive to be performed at large scale so in many countries because of it costs it may be restricted or even prohibited. Neutering and release strategies for stray dogs have been recommended similarly as used in the TNR for cats known as Animal Birth control (ABC) program (Totton et al., 2011). The ABC program involve the capture, surgical sterilization and rabies vaccination of stray dogs with the whole idea to replace the sexually intact, unvaccinated stray dog population with a smaller population of infertile healthier dogs in order to reduce the population of dogs in a given area. To be effective in that, the work has to be intensive, $70 \%$ of the dogs should be neutered during one breeding cycle, which is approximately about the next six months (Butcher, 1999; Reece, 2007). Success of ABC program in controlling the stray dog population has been state in India (Reece and Chawla, 2006; Totton et al., 2010). However, dogs are always dependent on humans and releasing them back to the streets, although a progressively reduction in its numbers may occurs, that does not improve their health and still have the potential risk to bites and transmission of diseases. Under this panorama, euthanasia may be necessary considered. Besides, free-roaming cat populations have a high intrinsic growth rate, and euthanasia has proved to be more effective at reducing its populations than trap-neuter-return programs (Andersen et al., 2004). Overcrowd of dog shelters because of recruitment of many dogs and lack of adoptions is also a reason of mass dog euthanasia.

A special mention is the dog meat consumption in Asian countries such as South Korea, China, Vietnan and Phillipines. In these countries eating dog is a socially acceptable practice. In South Korea for instance dog meat is eaten nationwide all year round. Their industry involves about 1,000,000 dogs killed yearly to supply the approximately 6,000 restaurants serving this food. A typical Korean dog slaughterhouse could have dogs ranging from poodles to beagles to Korean Jindo dogs; dogs are also imported from Laos to cover the demand. In China the Saint Bernard breed is becoming popular for food consumption for the fast growth of the puppies and animals are slaughtered between 6 and 12 months of age for best size and tenderness. Under these circumstances, the population of dogs may be dramatically reduced. The controversy in this case is not because of the consumption of dog meat itself or the results of this practice on reduce the population, but factors like cruelty involved with the killing. No country in the world consuming dog meat has developed a humane method of dog slaughter under intensive farming practices. Currently, cruel methods are being used including beating, strangling, boiling and bleed to death (by cutting holes in their paws) and sometimes dogs are skinned while still alive.

\section{Euthanasia in dogs}

In veterinary medicine the alternative to euthanasia is in many cases considered as a "clinical act"; it doesn't mean a failure in veterinary practice, but rather a prudent withdraws in time to avoid further suffering, when we know that there is no alternative to ensure an adequate quality of life. In general, euthanasia of dogs is banned except in special justified cases such as seriously or incurably ill or proven to be dangerous dogs. However, in many countries due to the legal classification of animals as personal property, the owner 
has the right of ownership over his animal so that the pet can selling or killed (Passantino et al., 2006). In this view a request for euthanasia is licit, whatever the animal's state of health may be. Euthanasia must be carried out exclusively by an experienced veterinarian. When euthanasia of a healthy owned dog is requested by its owner, the veterinarian should reproach such a request based on their professional ethic code and look for more appropriate options. Veterinarians counsel pet owners on daily basis and have the knowledge and "authority" to heal human culture so they may have an important role in reducing dog euthanasia (Scarlett et al., 2002). Relinquishing of dogs is the beginning to the "euthanasia route" and in many cases behavioral problems such as inappropriate elimination (Voith \& Borchel, 1982; Patronek et al., 1996), aggressive behavior (Patronek et al., 1996), and other behavioral problems are involve in the relinquishment. A study of dog euthanasia from Denmark in 1997-1998 showed that, of the 2,493 euthanized dogs surveyed, $23.6 \%$ were euthanased in response to behavioural problems (Mikkelsen \& Lund, 1999). A high proportion of adopted stray dogs from pounds are bringing back to the pounds for several reasons. In a dog pound from Italy, from 1,789 adopted dogs, 271 (15\%) where brought back because of behavioral problems (Mondelli et al., 2002)

Several societies such as the World Society for the Protection of Animals does not condone mass destruction as a control population measure of dogs and cats when there are circumstances when euthanasia is the most humane option. Animals considered for euthanasia should include those sick or dangerous. However, euthanasia can also be acceptable in animals unsuitable for homing or returned to the streets or to alleviate shelter overcrowding which compromise the welfare of animals held there (World Society for the Protection of Animals [WSPA], 2000). In Italy since 1991, national legislation does not permit euthanasia of unwanted roaming dogs unless they have an incurable condition or are proven to be dangerous. Unattended dogs are placed in long-term shelters in questionable conditions where they often remain for most of their lives (Dalla Villa et al., 2008). Consequences of such decisions may alter the dynamic of dog populations if no other control measures are considered to reduce the number of dogs, especially those stray. For instance, in animal shelters from Barcelona Spain in 2003 routine euthanasia of unclaimed stray animals was discontinued, due to a political decision of the city council. However the suspension of routine euthanasia was associated with a marked increase in the number of stray dogs. Canine distemper became endemic in the shelter until late 2004, due to a certain unwillingness to use euthanasia to control infection transmission (García-Rodríguez et al., 2008).

When euthanasia is considered, several methods are available for dogs but not all are considered acceptable (Close et al., 1997). However, because of the safety for personnel, efficacy and costs, the preferred method is the intravenous injection of sodium pentabarbitone (Table 1). Different methods for euthanasia in dogs are well described elsewhere however some methods remain controversial (Andrews et al., 1993). A reliable method will produce rapid loss of consciousness until death occurs. Regardless of the method used, it is important to minimize distress, anxiety and pain. It is compulsory to confirm the death of dog when euthanasia is performed before the body is disposed or left unattended. If an animal is not dead, another method of euthanasia should be performed. Finally the carcass should be disposed according to the local ruling legislation avoiding the risk of residues. Incineration is considered the safest way of carcass disposal. 


\begin{tabular}{|c|c|}
\hline Agent & Remarks \\
\hline Sodium Pentobarbitone & $\begin{array}{l}\text { Best option for intravenous injection. Intracardiac or } \\
\text { intrapulmonary routes of injection should not be used as they } \\
\text { are extremely painful, unless under full anaesthesia. }\end{array}$ \\
\hline T61 & $\begin{array}{l}\text { Very effective agent but only to be injected very slowly } \\
\text { intravenously. Animals may require sedation prior to } \\
\text { administration. It may cause convulsions in the unconscious } \\
\text { animal, which may be aesthetically unpleasant. }\end{array}$ \\
\hline Secobarbital/dibucaine & $\begin{array}{l}\text { Secobarbital is a short-acting analogue of thiamylol sodium, } \\
\text { whereas dibucaine is a highly toxic local anaesthetic causing } \\
\text { rapid loss of consciousness, loss of respiration and cardiac } \\
\text { arrest. The combination product produced a quiet and rapid } \\
\text { death. Dibucaine alone is not desirable for use for euthanasia. }\end{array}$ \\
\hline $\begin{array}{l}\text { Halothane, isoflurane, } \\
\text { enflurane }\end{array}$ & $\begin{array}{l}\text { These are all acceptable methods of euthanasia for carnivores. } \\
\text { Appropriate gas scavenging apparatus should be used to } \\
\text { prevent } \\
\text { operator exposure. }\end{array}$ \\
\hline Captive bolt & $\begin{array}{l}\text { Can be inhumane if shot is inaccurate and dog is only } \\
\text { wounded. Animal should be restrained. Personnel must be } \\
\text { trained in these techniques to ensure correct positioning of the } \\
\text { pistol and immediate death. No risk to operator (see free } \\
\text { bullet) unless risk of dog infected with rabies, due to potential } \\
\text { contact with brain issue. }\end{array}$ \\
\hline Electrocution & $\begin{array}{l}\text { This method may produce severe pain due to cardiac } \\
\text { fibrillation before onset of unconsciousness. Pain can also be } \\
\text { caused by violent extension of the limbs, head and neck and } \\
\text { may not be effective if insufficient current applied (a } \\
\text { considered lethal shock is } 1 \mathrm{kV} \text { passing from the ear to } \\
\text { hindleg) so the equipment must be regularly checked and } \\
\text { maintained to ensure correct voltage. Dogs should be } \\
\text { unconscious before being electrocuted by electrical stunning } \\
\text { (current through the brain to produce an instantaneous stun) } \\
\text { or anaesthesia. Death would result from current passed } \\
\text { through the heart of an unconscious. animal. Proper } \\
\text { equipment and trained operator is essential. May be hazardous } \\
\text { for operator, who should use protective equipment (boots and } \\
\text { gloves). Low cost. Death must be confirmed. }\end{array}$ \\
\hline Concussion & Only to be considered in small neonates \\
\hline Shooting & $\begin{array}{l}\text { Can be inhumane if shot is inaccurate and dog is only } \\
\text { wounded; dog may also escape. Skilled operator essential. Risk } \\
\text { of injury to operators and spectators. Not necessary to handle } \\
\text { or capture dog. } \\
\text { Brain tissue may be unavailable for rabies diagnosis. Shooting } \\
\text { of carnivores using a free bullet is only acceptable under field } \\
\text { conditions when no other methods can be used. Only } \\
\text { specialized marksmen should be used. }\end{array}$ \\
\hline
\end{tabular}

Table 1. Must accepted methods for euthanasia in dogs 
All the above mention agents or methods are in general fast and highly efficient. The following agents are unacceptable and are condemned for use as euthanasia agents in dogs: strychnine, nicotine, caffeine, magnesium sulfate, potassium chloride, cyclopropane, hydrogen cyanide gas, methoxyflurane, trichloroethylene, nitrous oxide cleaning agents, solvents, disinfectants and other toxins or salts, and all neuromuscular blocking agents. Other methods such as drowning, concussion (adults), decapitation, asphyxia, strangulation or air embolism are also not considered as euthanasic methods. When euthanasia is considered, besides the appropriate method used The World Organisation for Animal Health [OIE] (2010) suggests special attention to:

a. Restraint. When a dog needs to be restrained for euthanasia, this should always be done with full regard for operator security and animal welfare. Some euthanasia methods should be used in association with sedation or anaesthesia in order to be considered humane.

b. Special equipment. When special equipment is needed to perform euthanasia (e.g. gas chamber), the system should be designed for the purpose and regularly maintained in order to achieve operator security and animal welfare.

Because neonates and adults with impaired breathing or low blood pressure are resistant to hypoxia, methods that depend upon achieving a hypoxic state (e.g. CO2, CO, N2, Ar) should not be used. These methods should not be used in dogs aged less than 2 months, except to produce loss of consciousness and should be followed by another method to cause death. In general, neonates form carnivores should be treated as adults. Sodium pentobarbitone is the preferred method but concussion and cervical dislocation may be used in very small neonatal dogs and only in cases of emergency (OIE, 2010). However, operators must be well trained in the physical techniques to ensure that they are correctly and humanely carried out. When ovarian hysterectomies are performed, euthanasia of feti should be accomplished as soon as possible after removal from the dam.

\section{Ethical concerns of euthanasia in stray dogs and animal shelters}

Although in veterinary practice euthanasia in dogs is reasonably common, these "end of life decision" provoke an emotional period and in many instances ethical concerns occurs. For these reason, methods such as the undisclosed standardized client (USCs) and the measure of patient-centered consideration (MPCC) may reduce animal suffering and enhance the satisfaction and well-being of both clients and veterinarians (Nogueira et al., 2010).

However, when a healthy dog has to be euthanized a moral dilemma occurs in the profession. Dogs may be consider animals as sensitive beings, so they have the capacity to perceive pain and pleasure and are worthy of being under the protection of a law. Killing a healthy animal have legal consequences and may be considered a crime. In contrast euthanasia is legal in specific cases. For these reasons, people involved in dog pounds and dog shelters need to be aware of the use of euthanasia as part of the strategy dealing with dog overpopulation and be aware of the moral dilemma involved. Euthanasia only treats the symptoms but not the causes of the problems of overpopulation and should be considered as the last resource.

Three different scenarios of mass euthanasia of dogs to control its population may be found, dog pounds, animal shelters and municipal campaigns of dog population control. 


\subsection{Dog pounds}

Also called "public shelters" or "animal control agencies" are common in many developing countries where laws regulate and justify the mass euthanasia. Dog pounds activities are generally limited to the custody and euthanasia of stray animals and are commonly finance by tax found from the municipalities. The pickup and reception of surplus and stray o relinquished animals have the objective to avoid damage to the community. The OIE (2010) considers euthanasia as a method to reduce the number of stray dogs to an acceptable level in order to reduce the risk of rabies and other zoonotic diseases and to prevent harm to the environment and other animals.

An example of dog pound facilities is shown in Figure 2. Dog are protected for 3-10 days to give them the opportunity to be re-homed to their original owners or being adopted. However in dog pound, very few dogs are claimed and the adoption rate is very low or practically non-existing. Under these situation an overflow of dogs rapidly occurs and the quickest way to obtain space is by eliminate them by "strategic euthanasia". Since practically all dogs are euthanized, no moral conflicts arise by selecting candidates.

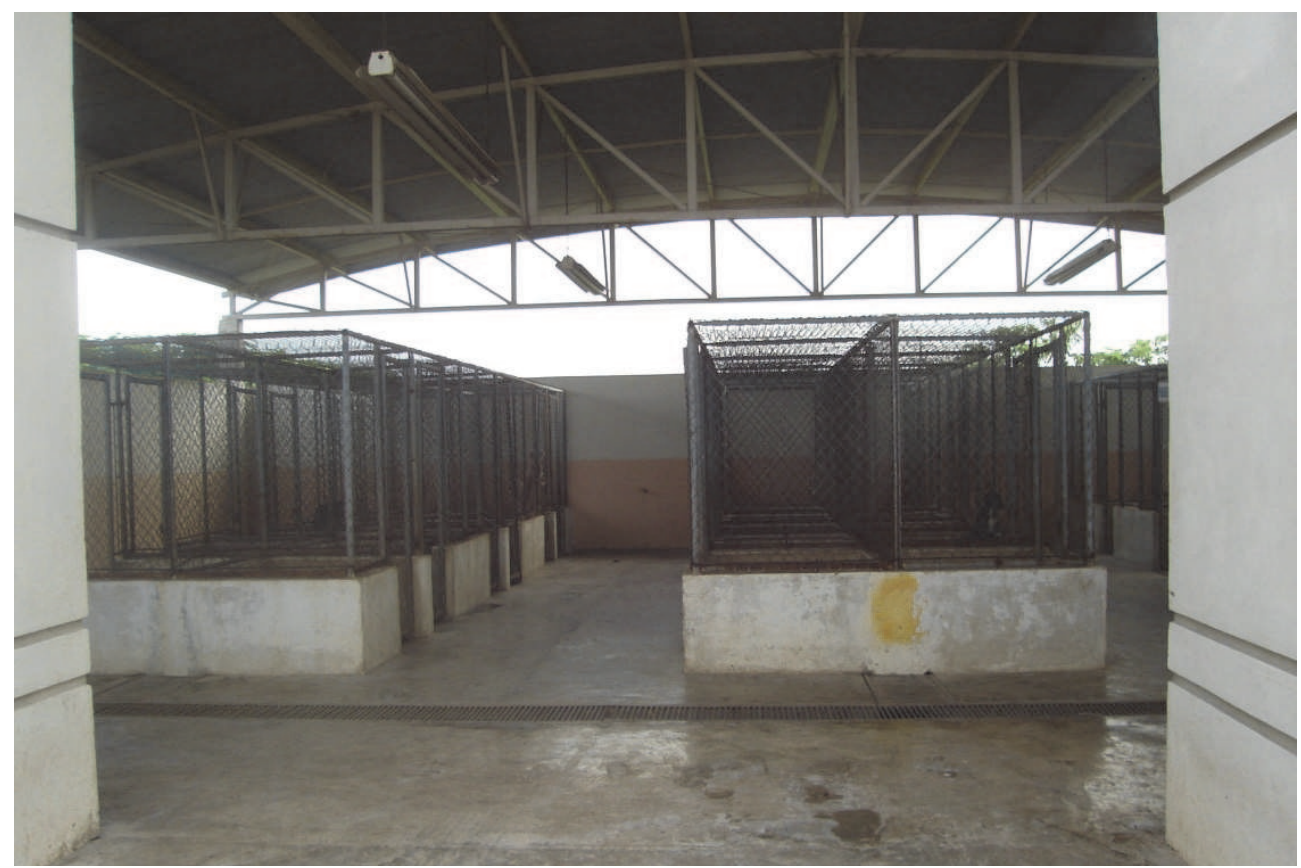

Fig. 2. A municipal dog pound building

Dogs that arrive in very bad conditions without few possibilities to be adopted should be immediately euthanized. In Figure 3 two typical case of dog going to immediate euthanasia are shown; in these cases there is no chance of treatment. It is estimated that $75 \%$ of the world's dog population are strays. Managing them presents a problem in many countries, and has serious implications for public health and animal welfare. Killing stray dogs often produces a short term effect, even when maximal catching rates (up to $24 \%$ of dog population/year) make no significant impact (WHO, 1988, 1990). Efforts of dog pounds 
should be focus on preventing these problems by public education including the supervision of breeding, management of behavioral problems and promoting the culture of adoption. In Barcelona Spain, with the formulation of a city Plan for Pet Animals, the activities were redirected, concentrating on services within the city limits and stimulating adoption. Participation of both professional and humane organizations was sought, premises were renovated, responsible ownership of animals was promoted, controlled urban colonies of cats were established, and adoptions become the cornerstone of policy, centering the activity of the pounds toward its clients. Changes in the dog pound's activity since 1998 reflects a clear decrease in the number of animals retained, as well as in the proportion subjected to euthanasia (from $83.4 \%$ of euthanasias of animals entered in 1993 to $47.2 \%$ in 2001). This decrease may reflect an improvement in the problem of stray animals. Besides, these developments have also resulted in a positive change in the relationship with the media and animal welfare organizations (Peracho et al., 2003).

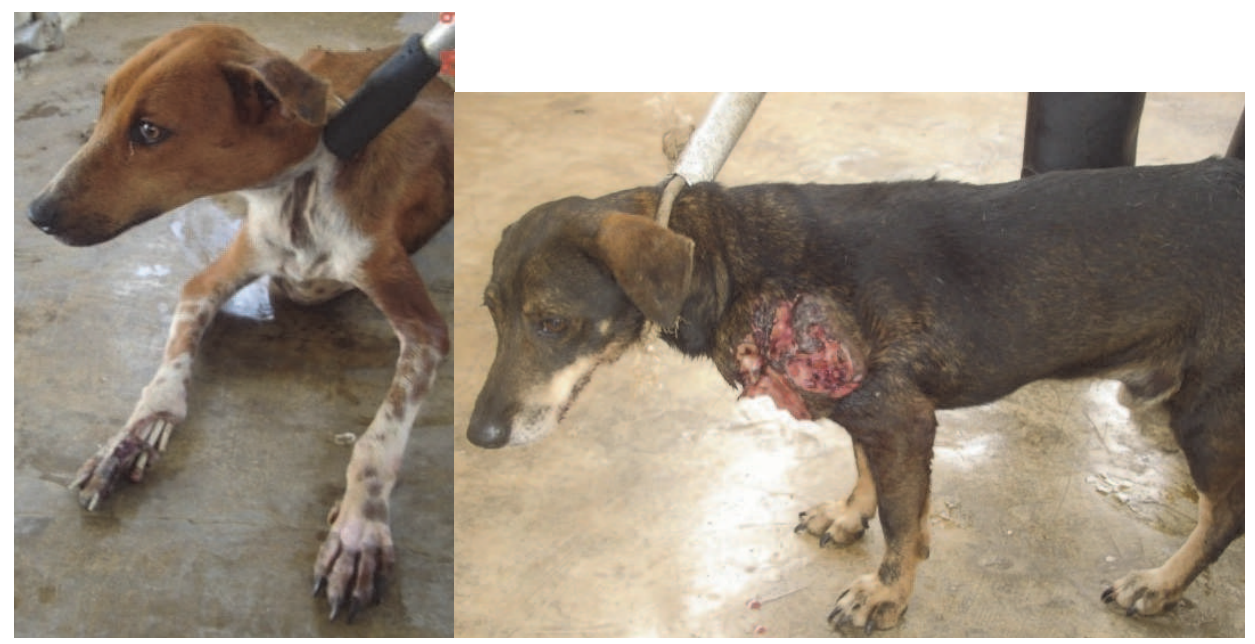

Fig. 3. Stray dogs from a dog pound apt for euthanasia

\subsection{Dog shelters}

Also called human agencies are usually non-profit agencies depending on charities and donations to fund their operations. In these agencies relinquished animals are accepted and educational programs on animal care and welfare to public are offer. Adoptions of dogs are also offered and this is fundamental for the flow of animals through the shelter. Ideally, no healthy, adoptable animal should be euthanized. However, euthanasia in dog shelters occurs frequently because of the flow of dogs is altered by the high income number of animals and limitations of space and funds, or when old age and terminal diseases requires to end a poor life quality. An estimation of euthanized rates in North American dog and cat shelters indicates figures of 10 to 20 million each year (Olson, 1990; Caras, 1993). In 2003, Michigan shelters discharged 140,653 dogs: Of these, 56,972 (40\%) were euthanized and $40,005(28 \%)$ were adopted (Bartlett et al., 2005). In Colorado shelters, after considerable efforts centered in increasing adoptions, increasing the number of dogs returned to owners by implementing licensing requirements and improving identification methods, education 
of public on animal welfare issues and subsidizing spay neuter programs, the number of unwanted dogs have decreased but after almost a decade, no changes in the euthanasia rate of dogs (3.7/1000 residents/year) have been observed indicating that the shelters dynamics of dogs appeared to reached an equilibrium with respect to euthanasia (Morris et al., 2011). A model suggests that the balance between supply and demand for dogs can be achieved such that euthanasia is never required (Frank, 2004).

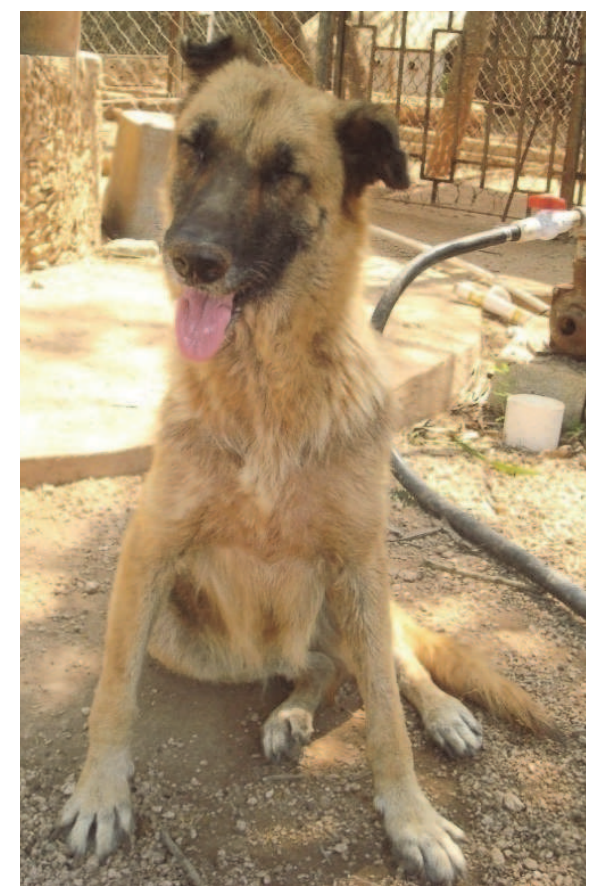

Fig. 4. A dog from a shelter considered for euthanasia

However, euthanasia is always required for the animals difficult to adopt (old, sick, unpopular breed, behavioral problem). As seen euthanasia in shelters is a used resource but it also generates moral issues. No kill shelter dog should be defined as one in where no adoptable dog is euthanize but where this resource may be used in old and dying dog in pain or suffering. In figure 4 an old dog in pain with bad life quality is shown. Although veterinarians have the professional knowledge and experience to euthanize dogs, other professionals, such as animal shelter workers, may also be trained to euthanize dogs. Killing shelters may bring a moral stress to their workers when dealing with euthanasia. Although workers realize that euthanasia of dog as a police to deal with over-population, this will not diminished the problem and they have to rationalize it even when they become enrolled to shelters with the idea of interacting and love caring of dogs. Euthanasia training for shelter workers also includes seminars on dealing with the irony that responsible animal care sometimes includes killing animals (Arluke, 1991).

The concept of canine health management is accord with the concept Shelter medicine or population medicine. Population medicine is based on setting production goal, identifying 
risk factors of disease, preventive disease and maximizing production. Production goals in companion animals would be an acceptable level of welfare and considerations of the incidence and prevalence of clinical and behavioral disease (Hurley, 2004). The implement of the shelter medicine in two Italian shelters (where laws do not currently allow euthanasia as a suitable method to control shelter population or used for scientific purposes) during three years and without admission of new dogs "closed system" resulted in improved dog health and welfare, as indicated by the significant reduction in both the prevalence and incidence of major pathologies during the next two years (Dalla Villa et al., 2008).

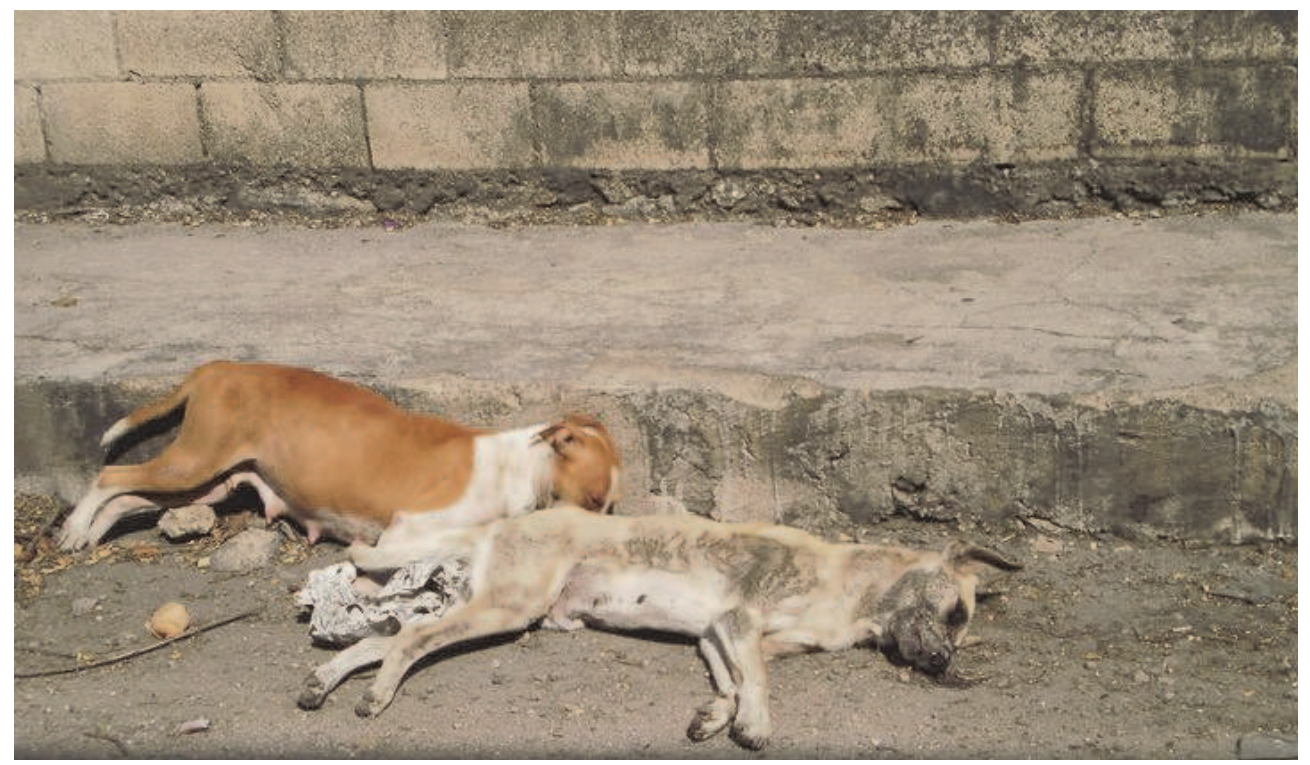

Fig. 5. Stray dogs poisoned during a municipal campaign

\subsection{Municipal campaigns}

Other scenario of mass destruction of dogs in order to control its population, specially stray dogs, is sometimes carried out in small rural municipalities using poisonous baits with strychnine or cyanide; strychnine causes violent convulsions and painful muscle contractions whereas cyanide pose extreme danger to personnel and the manner of death is aesthetically objectionable. Use of such method is totally unacceptable since are not considered euthanasic agents. In figure 5 an example of stray dogs poisoned during a campaign in Yucatán Mexico is shown; baits with strychnine were placed in the main streets were dogs were free roaming. Cats an opossums are also victims of the baits. Other variety of inhumane methods used in such campaigns include shooting, hanging and electrocution in a futile attempt to control the number of stray dogs. Such strategies are inhuman and potentially dangerous specially in kids and wild life consuming the baits and should be condemn. The prevention culture through education of the public should be considered by the local authorities to deal with this kind of problem.

In extreme situations for instance in provinces of Argentina, a recently promulgate law prohibit the function of dog pounds and euthanasia was banned in small animals, including 
animals with cases of terminal diseases or serious injuries (La Nación, 2011), these may result morally questioned because of the unnecessary suffering of the dog. In Mexico, despite the existence of laws regulating dog pounds and management of stray dogs (NOM-042-SSA22006), these are in most cases not conforming for several reasons. Many cases of mass killing of dogs and cats are reported throughout the country and condemned by the society. In some circumstances like in a small town in Mexico (Tlaxiaco, Oaxaca), with the increasing number of stray dogs (considered as pests), the Municipal Health Bureau announced that it expects the slaughter of over a thousand dogs in the streets because they are a source of pollution and the number of attacks to humans have been increasing for the large population of these pets. The sterilization campaigns which are made in order to prevent further proliferation of stray dogs in Tlaxiaco has been very erratic and no more than 55 animals had neutered, not even $10 \%$ of the estimated population. This is an example of municipal mismanagement and the consequent failure of campaign to sterilize dogs and cats, and most of all, a failure of public education about responsible pet ownership. In a different context in the Jaltenco municipality of Mexico city, were massacred with machetes and beaten to death around 30 dogs and cats that were under guard in a separate animal protection. Hooded men in black, with the approval of municipal police and some neighbors, the animals were attacked, leaving them very badly wounded amputees under cries of pain and fear. Only 12 of them managed to recover. This is an example of irresponsible brutality of ignorant authorities dealing with the problem of dog overpopulation.

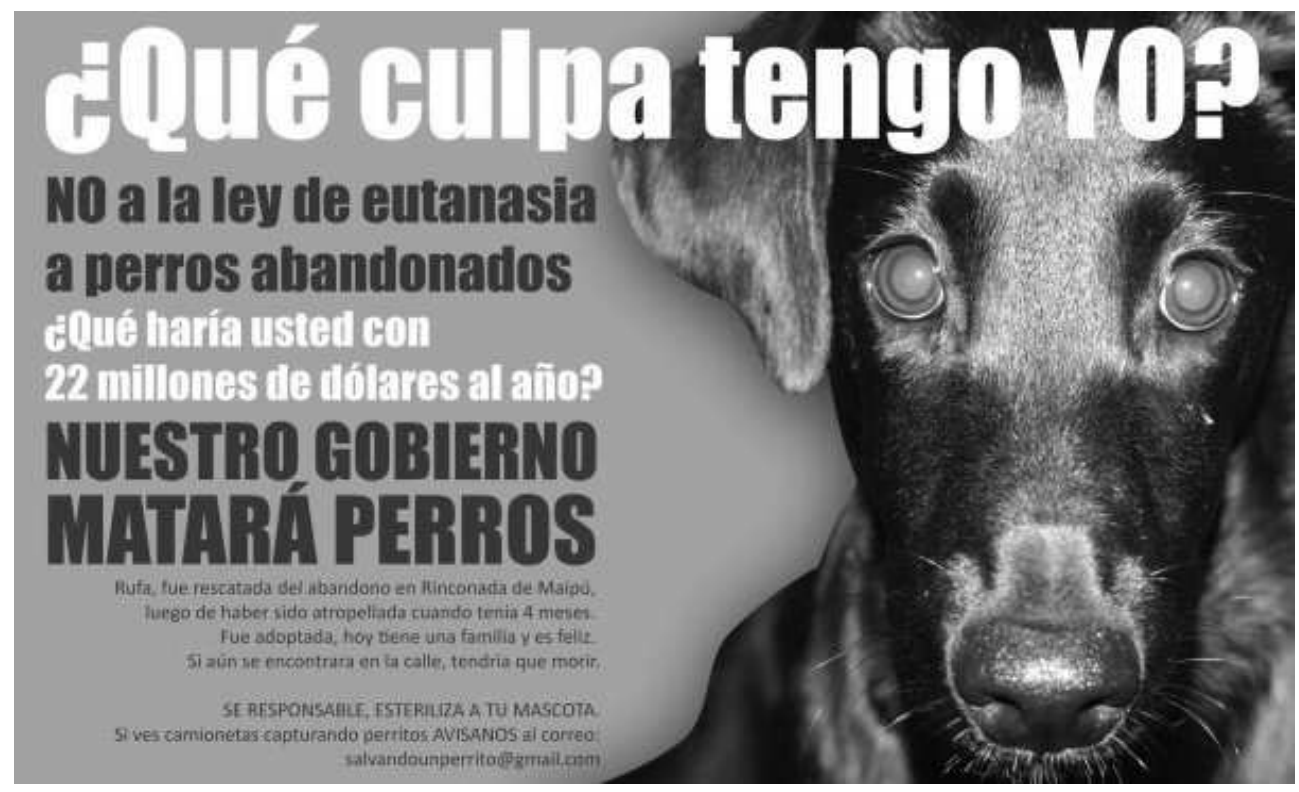

Fig. 6. Signal of protest against the decision of killing dogs in the city of Neuquen, Argentina. From the text "Why is my fault? No to the euthanasia law against stray dogs. What would you do with 22 millions of dollars a year? Our government will kill dogs" (available at: www.taringa.net/posts/solidaridad/6490679/Firma-el-petitorio-en-repudioa-la-matanza-en-Neuquen_.html) 
Fortunately, the society and animal protection associations are aware of these activities and accuse and expose the authorities responsible of such strategies to control stray dog populations. An example of society claims against massive dog killing is seen in the province of Neuquen in the Patagonia region of Argentina. After an outbreak of leptospirosis, a municipal resolution to sacrifice over 1100 dogs was announced. The resolution planned for the coming five days sacrificing 220 dogs, many of them delivered by their owners. These woke up the action from neighbors and animal welfare groups across the country. Authorities said that they will not kill animals, but called the neighbors to take charge of homeless pets. An example of protest and call to the society against this resolution is showed in figure 6 .

\section{Conclusion}

The use of euthanasia in control programs of the canine population generally tends to generate controversy and misinterpretation of the criteria recommended by different agencies. In general society strongly opposes to euthanasia and condemns governments that employ this strategy as a means of dog population control. Euthanasia is only a temporal remedy to cure the symptoms rather than causes of the problem of overpopulation, and should be the last resource to use at the end of a long process of evaluation. Euthanasia may be required in specific scenarios to balance the flow of dog overcrowd, to reduce the risk of zoonotic transmission and damage to the environment and to avoid unnecessary suffering. However, ethical concerns come about when healthy animals have to be killed. Nothing is going to solve the dog overpopulation problem except the capacity of humans to understand the situation and take actions avoiding the born of unwanted puppies and become responsible owners avoiding the relinquishing of their pets.

\section{Acknowledgments}

Authors would like to thank the Dog pound (Canine \& Feline Control Center) from the municipality of Merida Yucatan, Mexico, to the Arqta Silvia Cortés from the dog shelter "Evolución" and to Mrs Marcia Lara de Moreno from AMEDEA (Asociación Mexicana por los Derechos de los Animales, A.C. Yucatán) for their kindness collaboration and permission to take pictures included in this chapter.

\section{References}

Andersen, M.C.; Martin, B.J. \& Roemer G.W (2004). Use of matrix population models to estimate the efficacy of euthanasia versus trap-neuter-return for management of free-roaming cats. Journal of the American Veterinary Medical Association, Vol.225, No.12, (December 2004), pp. 1871-1876, ISSN 0003-1488

Andrews, E.J.; Bennett, T.; Clark, J.D.; Houpt, K.A.; Pascoe, P.J.; Robinson, G.W. \& Boyce, J.R. (1993). Report of the AVMA panel on euthanasia. Journal of the American Veterinary Medical Association, Vol.202, No.2, (January 1993), pp. 229-249, ISSN $0003-$ 1488

Arluke, A. (1991). Coping with euthanasia: a case study of shelters culture. Journal of the American Veterinary Medical Association, Vol.198, No.7, (April, 1991), pp. 1176-1191, ISSN 0003-1488 
Bartlett, P.C.; Bartlett, A.; Walshaw, S. \& Halstead, S. (2005). Rates of Euthanasia and Adoption for Dogs and Cats in Michigan Animal Shelters Journal of Applied Animal Welfare Science, Vol.8, No.2, (January, 2005), pp. 97-104. ISSN 1088-8705

Brooks, R. (1990). Survey of the dog population in Zimbabwe and its levels of rabies vaccination. Veterinary Record, Vol.127, No.24, (December, 1990), pp. 592-596. ISSN 0042-4900

Butcher, R. (1999). Stray dogs- a worldwide problem. Journal of Small Animal Practice, Vol.40, No.9, (September, 1999), pp. 458-459. ISSN 0022-4510

Caras, R. (1993). One generation away from humanity. Journal of the American Veterinary Medical Association, Vol.202, No.6, (March, 1993), pp. 910-912. ISSN 0003-1488

Close, B.; Banister, K.; Baumans, V.; Bernoth, E.M.; Bromage, N.; Bunyan, J.; Erhardt, W.; Flecknell, P.; Gregory, N.; Hackbarth, H.; Morton, D. \& Warwick, C. (1997). Recommendations for euthanasia of experimental animals: Part 2. Laboratory Animals Vol.31. No.1, (January, 1997), pp. 1-32. ISSN 0023-6772

Dalla Villa, P.; Kahn, S.; Stuardo, L.; Iannetti, L.; Di Nardo, A. \& Serpell, J.A. (2010). Freeroaming dog control among OIE-member countries. Preventive Veterinary Medicine, Vol.97, No.1, (August, 2010), pp. 58-63. ISSN 0167-5877

Dalla Villa, P.; Iannetti, L.; Podaliri Vulpiani, M.; Maitino, A.; Trentini, R.; Del Papa, S.A. (2008). A management model applied in two 'no-kill' dog shelters in central Italy: use of population medicine for three consecutive years. Veterinary Italy, Vol.44, No.2, (April, 2008) pp. 347-359. ISSN 0505-401X

Fielding, W.J. \& Plumridge, S.J. (2005). Characteristics of owned dogs on the island of New Providence, The Bahamas. Journal of Applied Animal Welfare Science, Vol.8, No.4, pp. 245-260. ISSN 1088-8705

Frank, J. (2004). An interactive model of human and companion animal dynamics: the ecology and economics of dog overpopulation and the human cost of addressing the problem. Journal of Human Ecology, Vol.32, No.1, (February, 2004) pp. 107-130. ISSN 0300-7839

García-Rodríguez, A.; Peracho, V.; Villalbí, J.R.; Bouis, S.; Duràn, J. \& Guix J. (2008). Avances en la gestión de un centro de acogida de animales de compañía. Gaceta Sanitaria Vol.22, No.1, (July, 2007) pp. 76-78. ISSN 0213-9111

Hsu, Y.; Severinghaus, L.L. \& Serpell, J.A. (2003). Dog keeping in Taiwan: its contribution to the problem of free-roaming dogs. Journal of Applied Animal Welfare Science, Vol.6, No.1, pp. 1-23. ISSN 1088-8705

Hurley, K.F. (2004). Implementing a population health plan in an animal shelter: goal setting, data collection and monitoring, and policy development. In: Shelter Medicine for Veterinarians and Staff. Miller L. \& Zawistowski (Ed.), pp. 211-234, Blackwell Publishing Professional, ISBN 0-8138-24486, Oxord, UK.

La Nación.com, (December, 2016). Prohíben perreras y la eutanasia de mascotas. In: La Nación, 12.02.2011. Available from: http//www.lanacion.com.ar/866148-prohibenperreras-y-la-eutanasia-de-mascotas.

Margawani, K.R. \& Robertson, I.D. (1995). A survey of urban pet ownership in Bali. Veterinary Record, Vol.137, No.19, (November, 1995) pp. 486-488. ISSN 0042-4900

Mikkelsen, J. \& Lund, J.D. (1999). Euthanasia of dogs because of behavioural problems. An epidemiological study on euthanasia of dogs in Denmark-with particular reference 
to aggression problems. Dansk Veterinærtidsskrift Vol.82, No.11, pp. 474-479. ISSN 0106-6854.

Mondelli, F.; Levi, D.; Magistrelli, S.; Prato Previde, E. \& Valsecchi, P. (2002). Why people brings back to the pound? A questionnaire study in Milan Italy. Proceedings of the British Society of Animal Science. pp. 65. ISBN 0906562 392. Published by BSAS, York UK, April, 2002.

Morris, K.N.; Wolf, J.L. \& Gies, D.L. (2011). Trends in intake and outcome data for animal shelters in Colorado, 2000 to 2007. Journal of the American Veterinary Medical Association, Vol.238, No.3, (February, 2009) pp. 329-336. ISSN 0003-1488

Nogueira, B.L.J.; Adams, C.L.; Bonnet, B.N.; Shaw, J.R. \& Ribble, C.S. (2010). Use of the measure of patient-centered communication to analyze euthanasia discussion in companion animals practice. Journal of the American Veterinary Medical Association. Vol,237, No.11, (December, 2010) pp. 1275-1287. ISSN 0003-1488

OIE (July, 2010). Stray dog population control. In: Terrestrial Animal Health Code 6.03.2011. Available from:

http/ / www.oie.int/index.php?id=169\&L=0\&htmfile=chapitre_1.7.7.htm

Olson, P.N. (1990). Concerned about euthanasia of healthy homeless animals (Letter). Journal of the American Veterinary Medical Association Vol.196, No.1, (January, 1990) pp. 10. ISSN 0003-1488

Orihuela, T.A. \& Solano, V.J. (1995). Demographics of the owned dog population in Miacatlan, Mor. Mexico. Anthrozoös, Vol.8, No.3, (January, 1995) pp. 171-175. ISSN 0892-7936

Passantino, A.; Fenga, C.; Morciano, C.; Morelli, C.; Russo, M.; Di Pietro, C. \& Passantino, M. (2006) Euthanasia of companion animals: a legal and ethical analysis. Annali dell Istituto Superiore di Sanita. , Vol.42, No.4, (July, 2006) pp. 491-495. ISSN 0021-2571

Patronek, G.J. \& Rowan, A.N. (1995) Determining dog and cat numbers and population dynamics. Anthrozoös Vol.8, No.4 (January, 1995) pp. 199-205. ISSN 0892-7936

Patronek, G.J.; Glickman, L.T.; Beck, A.M.; McCabe, G.P. \& Ecker, C. (1996). Risk factors for relinquishment of dogs to an animal shelter. Journal America Veterinary Medical Association, Vol.209, No.3, (August, 1996) pp. 572-581. ISSN 0003-1488

Peracho, V.; Villalbí, J.R.; Llebaría, X.; Armengou, J.M. \& Guix, J. (2003). De la perrera municipal al centro de acogida de animales de compañía de Barcelona. Gaceta Sanitaria, Vol.17, No.6 (September, 2003) pp. 515-519. ISSN 0213-9111

Reece, J.F. \& Chawla, S.K. (2006). Control of rabies in Jaipur, India by the sterilisation and vaccination of neighbourhood dogs. Veterinary Record, Vol.159, No.16 (September, 2006) pp. 379-383. ISSN 0042-4900

Reece, J.F. (2007). Rabies in India: an ABC approach to combating the disease in street dogs. Veterinary Record, Vol.161, No.9 (September, 2007) pp. 292-293. ISSN 0042-4900

Scarlett, J.M.; Salman, M.D.; New, J.G. \& Kass, P.H. (2002). The role of veterinary practitioners in reducing dog and cat relinquishments and euthanasias. Journal of the American Veterinary Medical Association, Vol.220, No.3 (February, 2002) pp. 306311. ISSN 0003-1488

Totton, S.C.; Wandeler, A.I.; Ribble, C.S.; Rosatte, R.C. \& McEwen, S.A. (2011). Stray dog population health in Jodhpur India in the wake of animal birth control (ABC) program. Preventive Veterinary Medicine, Vol.98, No. 2-3 (February, 2001) pp. 215220. ISSN 0167-5877 
Totton, S.C.; Wandeler, A.I.; Zinsstag, J.; Bauch, C.T.; Ribble, C.S.; Rosatte, R.C. \& McEwen, S.A. (2010). Stray dog population demographics in Jodhpur, India following a population control/rabies vaccination program. Preventive Veterinary Medicine, Vol.97, No.1 (August, 2010) pp. 51-57. ISSN 0167-5877

Voith, V.L. \& Borchelt, P.L. (1982) Diagnosis and treatment of elimination behavior problems in dogs. Veterinary Clinics of North America Small Animal Practice, Vol.World Health Organization (1990). Consultation of dog population management. WHO.ZOON 90.166, 6-37

World Health Organization (1988). Consultation on dog ecology studies related to rabies control. WHO/Rab.Res 88.25

WSPA (2000). Humane euthanasia for dogs and cats. Royal Society for the Prevention of Cruelty to Animals. pp. 1-4.

ISAR (1991). A prime source of canine overpopulation. In: International Society of Animals Rights, law and education serving animals- Special report. 11.02.2011, Available from: http//www. isaronline.org.citymax.com/f/a.pdf 


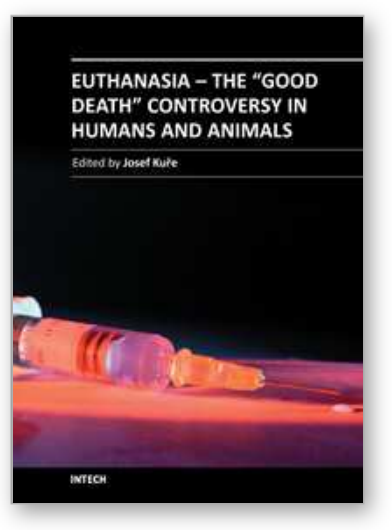

\author{
Euthanasia - The "Good Death" Controversy in Humans and \\ Animals \\ Edited by Prof. Josef KuÅ ${ }^{T M} \mathrm{e}$
}

ISBN 978-953-307-260-9

Hard cover, 248 pages

Publisher InTech

Published online 15, September, 2011

Published in print edition September, 2011

No one really wants to die, or do they? From classical times to our post-modern era of medical high tech, societies have struggled with the thorny issue of euthanasia, and what it entails. Who shall be entitled to a "good death" and in what form shall it arrive? This book provides the reader with insight and enlightenment on the medical, philosophical, social, cultural and existential aspects of "good death" amid our digitized, individualized and ageing society, hampered by rising health care costs but unchained from one standardized level of care.

\title{
How to reference
}

In order to correctly reference this scholarly work, feel free to copy and paste the following:

Antonio Ortega-Pacheco and Matilde Jiménez-Coello (2011). Debate For and Against Euthanasia in the Control of Dog Populations, Euthanasia - The "Good Death" Controversy in Humans and Animals, Prof. Josef KuÅ ${ }^{T M}$ e (Ed.), ISBN: 978-953-307-260-9, InTech, Available from:

http://www.intechopen.com/books/euthanasia-the-good-death-controversy-in-humans-and-animals/debate-forand-against-euthanasia-in-the-control-of-dog-populations

\section{INTECH}

open science | open minds

\section{InTech Europe}

University Campus STeP Ri

Slavka Krautzeka 83/A

51000 Rijeka, Croatia

Phone: +385 (51) 770447

Fax: +385 (51) 686166

www.intechopen.com

\section{InTech China}

Unit 405, Office Block, Hotel Equatorial Shanghai

No.65, Yan An Road (West), Shanghai, 200040, China

中国上海市延安西路65号上海国际贵都大饭店办公楼405单元

Phone: +86-21-62489820

Fax: +86-21-62489821 
(C) 2011 The Author(s). Licensee IntechOpen. This chapter is distributed under the terms of the Creative Commons Attribution-NonCommercialShareAlike-3.0 License, which permits use, distribution and reproduction for non-commercial purposes, provided the original is properly cited and derivative works building on this content are distributed under the same license. 